\title{
Pattern of Malocclusion among Patients Seeking Orthodontic Treatment at Hospitals and Private Clinics of Province 2, Nepal
}

\author{
Dr. Kaushal K Singh', Dr. Binita Singh², Dr. Rajiv Yadav ${ }^{3}$ \\ 'Lecturer, Department of Orthodontics and Dentofacial Orthopedics, \\ National Medical College Teaching Hospital, Birgunj, Nepal. \\ ${ }^{2}$ Lecturer, Department of Orthodontics and Dentofacial Orthopedics, M.B. Kedia Dental College, Birgunj, Nepal. \\ ${ }^{3}$ Associate professor, Department of Orthodontics and Dentofacial Orthopedics, Institute of Medicine,
} Tribhuvan University, Kathmandu, Nepal

Corresponding author: Dr. Kaushal K Singh,Email: kausalcr@gmail.com

\section{ABSTRACT}

Introduction: Malocclusion affect the esthetic, function of the patients, so they seek orthodontic treatment for normal function and healthy and beautiful smile. Increase in public awareness and availability of orthodontic specialty services have led to increasing number of orthodontic patients in specialty clinics and hospitals. The objective of this study is to examine the pattern of malocclusion in the patients visiting medical and dental teaching hospitals and dental clinics and to measure the different Angle's classification of malocclusion with discrepancies in all three planes.

Materials and Method: Three hundred seventeen acceptable study casts were selected from 403 case records of orthodontic patients who visited the different hospitals and private clinics of Province 2, Nepal. A standard guidance of Angle's classification was used to classify the cases and casts were measured to record the data. Different Angle's classification of malocclusion with discrepancies in all three planes was studied. Descriptive statistics (frequency, percentage, mean and SD) and inferential statistics (chi square and fisher exact test) was used to find out the association between occlusal traits and demographic variables.

Result: According to the Angle's classification of malocclusion, most of the patient's cast $65.9 \%$ were of class I, followed by class II $31.8 \%$, class III $5.3 \%$ occlusion pattern. Among the class II malocclusion, class II division 1 malocclusion was more prevalent $(86.13 \%)$. Under space discrepancies, crowding of teeth was present in $42.58 \%$ of patient. Of the total teeth crowding patient, $70.3 \%$ had crowding of teeth in both the arches followed by only mandibular arch $(25.18 \%)$. There is statistically significant association between the age and the occlusal traits like crowding ( $p$ value 0.008 ), spacing ( $p$ value 0.000 ) and overjet ( $p$ value 0.000 ) at 0.01 level of significance.

Conclusion: Angle's class I was the most prevalent malocclusion followed by class II and class III. Increased overjet was the commonest occlusal trait. There was statistically significant association between the age and occlusal traits like crowding, spacing and overjet.

KEYWORDS: Angle's classification, Malocclusion, Occlusal traits, Orthodontics

\section{INTRODUCTION}

Malocclusion has been a problem for some individual since antiquity and attempts to correct this disorder go back at least to 1000 BC. ${ }^{1}$ Malocclusion is not considered as a disease but as a normal deviated condition. Evidence shows that it was related to the whole physical health and quality of life. WHO (1987) defined malocclusion as an handicapping dentofacial anomalies causing disfigurement or impending function and may require treatment when the defect was likely to be a cause of patients' physical and emotional wellbeing. ${ }^{2}$ Malocclusion affect the esthetic, function of the patients, so they seek orthodontic treatment for normal function and healthy and beautiful smile. Increase in public awareness and availability of orthodontic specialty services have led to increasing number of orthodontic patients in specialty clinics and hospitals. In order to provide a quality orthodontic 
treatment at any locality, the knowledge about prevalence of malocclusion and its' trait is utmost. Nepal is a landlocked country with diverse ethnic population, culture, climate and environment. The distribution of different malocclusions in Nepal might be different from rest of the world. Similarly, the distribution of different malocclusions in Province 2 might be different from rest of the Provinces of Nepal. This study, thus, aim to highlight the prevalence of malocclusion and its' trait in province 2 .

\section{MATERIALS AND METHOD}

This is a cross sectional study which included orthodontic patients' pretreatment dental cast who visited different hospitals and private clinics of Province 2, Nepal from September 2019 to February 2020. Three hundred seventeen acceptable study casts were selected from 403 casts who met the set inclusion criteria. The subjects ranged from 9 to 40 years. The inclusion criteria were: (1) permanent dentition with fully erupted intact first molar, (2) patient willing for orthodontic treatment, (3) no history of previous orthodontic treatment, (4) absence of craniofacial anomalies. A standard guidance of Angle's classification was used to classify the cases as class I, class II, class III. Dental casts were examined and measured to record the data. Different Angle's classification of malocclusion with discrepancies in all three planes was studied. Several traits of malocclusion included in the study were: over jet, spacing, crowding, deep bite, open bite, bimaxillary protrusion, cross bite and scissor bite. Missing teeth and retained deciduous teeth were also recorded. Amount of overjet was measured in millimeters between two antagonistic anterior teeth (central or lateral incisor) measured from the facial surface of the most lingual mandibular tooth to the middle incisal edge of a more facially positioned maxillary tooth. An overjet $\geq 3 \mathrm{~mm}$ was considered to be an increased overjet. The term negative overjet was used if both the left and right maxillary central incisors were in palatal occlusion. ${ }^{3-5}$ Overbite was measured in millimeters and recorded as the overlap of the mandibular anterior teeth by the maxillary anterior teeth. A pencil mark was done on the tooth indicating the extent of the overlap which facilitated the measurement. The overbite was considered normal when the linear measurement was between 0 to $3 \mathrm{~mm}$, deep overbite if $>3 \mathrm{~mm}$ The overbite less than $0 \mathrm{~mm}$ was noted as anterior open bite. ${ }^{3-5}$ The amount of an open bite was measured directly in millimeters between the incisal edges of the antagonistic anterior teeth. Authors were themselves involved in data collection after getting the ethical clearance from IRC NMC (F-NMC/407/075/076). Written formal permission was obtained from the concerned institute, hospitals and private clinics. The collected data were entered into SPSS and analyzed using descriptive statistics (frequency, percentage, mean and SD) and inferential statistics (Pearson's Chi square and fisher exact test) was performed to justify the result using SPSS version 25 .

\section{RESULT}

A total of 317 patients' cast was included in the study. Among them, most of the respondents $65.6 \%$ were in the age group of 9-18years with Mean age $\pm S D=17.68 \pm 5.21$. Regarding gender, two-third of the respondent $66.6 \%$ were female. Similarly, $87.4 \%$ of the respondents belonged to Hindu religion.

According to the Angle's classification of malocclusion, most of the patient's cast $65.9 \%$ were of class I, followed by class II $31.8 \%$, class III $5.3 \%$ occlusion pattern. Among the class II malocclusion, class II division 1 malocclusion was more prevalent (86.13\%) (Table 1).

Similarly, class I (65\%) canine relation was more common followed by class II (31.9\%) and class III (3.2\%). The prevalence of impacted teeth was $2.8 \%$.

Out of 317 patient's cast examined, $3.5 \%$ (11) had retained deciduous teeth. The most common retained deciduous teeth were maxillary canine.

Table 1: Distribution of Respondents according to Pattern of Malocclusion

$n=317$

\begin{tabular}{|l|l|l|}
\hline Pattern of Malocclusion & Frequency & Percentage \\
\hline Class I & 209 & 65.9 \\
\hline Class II & 101 & 31.9 \\
\hline Class II Division 1 & 87 & 86.1 \\
\hline Class II Division2 & 14 & 13.9 \\
\hline Class III & 07 & 2.2 \\
\hline
\end{tabular}

Under space discrepancies, crowding of teeth was present in $42.58 \%$ of patient. Of the total teeth crowding patient, $70.3 \%$ had crowding of teeth in both the arches followed by only mandibular arch (25.18\%).

Spacing was present in $34.38 \%$ patient with spacing being more commonly present in maxillary arch (64.22\%). 
The prevalence of missing teeth observed in the study was $8.6 \%$. among the missing teeth, maxillary central incisor teeth were most commonly missing followed by mandibular lateral incisor, mandibular second premolar and maxillary incisors in descending order.

Crossbite and scissor bite was present in $7.3 \%$ and $15.8 \%$ of the patient respectively.

Bimaxillary protrusion was present in $17.7 \%$.

There was increased overjet in $60.6 \%$ and deep overbite was seen in $49.2 \%$ of the patient. Negative overjet was present in $2.8 \%$ of the respondent. Similarly, $2.5 \%$ of the respondent had open bite.

Pearson Chi square test and Fisher exact test was conducted to find out the association between the different occlusal traits and gender and age which showed that there is statistical significant association between the age and the occlusal traits like crowding ( $p$ value 0.008 ), spacing ( $p$ value 0.000 ) and overjet ( $p$ value 0.000 ) at 0.01 level of significance and none of the attributes of malocclusion were significantly related with gender at $p<0.05$. (Table 2 and 3 )

Table 2: Association between Occlusal Traits and Age

\begin{tabular}{|c|c|c|c|c|}
\hline \multirow{2}{*}{$\begin{array}{l}\text { Occlusal } \\
\text { Traits }\end{array}$} & \multicolumn{3}{|c|}{ Age in years } & \multirow{2}{*}{$\begin{array}{l}P \\
\text { value }\end{array}$} \\
\hline & $\begin{array}{l}9-18 \mathrm{~N} \\
(\%)\end{array}$ & & $\begin{array}{l}>28 \mathrm{~N} \\
(\%)\end{array}$ & \\
\hline $\begin{array}{l}\text { Crowding\# } \\
\text { Maxillary } \\
\text { Mandibular } \\
\text { Both } \\
\text { None }\end{array}$ & $\begin{array}{l}3(1.4) \\
19(9.1) \\
73(35.1) \\
113(54.3)\end{array}$ & $\begin{array}{l}2(2.0) \\
15(15.3) \\
22(22.4) \\
59(60.2)\end{array}$ & $\begin{array}{l}1(9.1) \\
0(0.0) \\
0(0.0) \\
10(90.9)\end{array}$ & $0.008 *$ \\
\hline $\begin{array}{l}\text { Spacing \# } \\
\text { Maxillary } \\
\text { Mandibular } \\
\text { Both } \\
\text { None }\end{array}$ & $\begin{array}{l}39(18.8) \\
2(1.0) \\
21(10.1) \\
146(70.2)\end{array}$ & $\begin{array}{l}29(29.6) \\
0(0.0) \\
12(12.2) \\
57(58.2)\end{array}$ & \begin{tabular}{|l}
$2(18.2)$ \\
$4(36.4)$ \\
$0(0.0)$ \\
$5(45.5)$ \\
\end{tabular} & 0.000 * \\
\hline $\begin{array}{l}\text { Overjet\# } \\
\text { Normal } \\
\text { Increased } \\
\text { Negative }\end{array}$ & $\begin{array}{l}67(32.2) \\
134(64.4) \\
7(3.4)\end{array}$ & $\begin{array}{l}41(41.8) \\
57(58.2) \\
0(0.0)\end{array}$ & \begin{tabular}{|l|}
$8(72.7)$ \\
$1(9.1)$ \\
$2(18.2)$ \\
\end{tabular} & $0.000 *$ \\
\hline $\begin{array}{l}\text { Deepbite\# } \\
\text { Normal } \\
\text { Increased } \\
\text { Openbite }\end{array}$ & $\begin{array}{l}102(49.0) \\
102(49.0) \\
4(1.9)\end{array}$ & $\begin{array}{l}44(44.9) \\
51(52.0) \\
3(3.1)\end{array}$ & \begin{tabular}{|l}
$7(63.6)$ \\
$3(27.3)$ \\
$1(9.1)$
\end{tabular} & 0.267 \\
\hline $\begin{array}{l}\text { Molarrelation\# } \\
\text { Class I } \\
\text { Class II } \\
\text { Class III }\end{array}$ & $\begin{array}{l}131(63.0) \\
70(33.7) \\
7(3.4)\end{array}$ & $\begin{array}{l}68(69.4) \\
30(30.6) \\
0(0.0)\end{array}$ & $\begin{array}{l}10(90.9) \\
1(9.1) \\
0(0.0)\end{array}$ & 0.130 \\
\hline
\end{tabular}

*Statistically Significant at the level of $(p=0.01)$, \#-fisher exact test
Table 3: Association between Occlusal Traits and Gender

\begin{tabular}{|l|l|l|l|}
\hline \multirow{2}{*}{ Occlusal Traits } & \multicolumn{2}{|c|}{ Gender } & P \\
\cline { 2 - 3 } & $\begin{array}{l}\text { Male } \\
\mathrm{N}(\%)\end{array}$ & $\begin{array}{l}\text { Female } \\
\mathrm{N}(\%)\end{array}$ & \\
\hline Crowding\# & & & \\
Maxillary & $2(1.9)$ & $4(1.9)$ & \\
Mandibular & $13(12.3)$ & $21(10.0)$ & 0.672 \\
Both & $35(33.0)$ & $60(28.4)$ & \\
None & $56(52.8)$ & $126(59.7)$ & \\
\hline Spacing \# & & & \\
Maxillary & $21(19.8)$ & $49(23.2)$ & \\
Mandibular & $4(3.8)$ & $2(0.9)$ & 0.343 \\
Both & $12(11.3)$ & $21(10.0)$ & \\
None & $69(65.1)$ & $139(65.9)$ & \\
\hline Overjet\#\# & & & \\
Normal & $36(34.0)$ & $80(37.9)$ & 0.648 \\
Increased & $66(62.3)$ & $126(59.7)$ & \\
Negative & $4(3.8)$ & $5(2.4)$ & \\
\hline Deepbite\#\# & & & \\
Normal & $42(39.6)$ & $111(52.6)$ & 0.064 \\
Increased & $62(58.5)$ & $94(44.5)$ & \\
Openbite & $2(1.9)$ & $6(2.8)$ & \\
\hline Molar relation\# & & & \\
Class I & $74(69.8)$ & $135(64.0)$ & 0.474 \\
Class II & $31(29.2)$ & $70(33.2)$ & \\
Class III & $1(0.9)$ & $6(2.8)$ & \\
\hline
\end{tabular}

Level of Significance at $<0.05$, \# fisher exact test, \#\# chi square test

\section{DISCUSSION}

The result of present study showed that females (66.6\%) are more concern for the orthodontic treatment which is similar to the data reported by JN Sharma ${ }^{6}$ (two-third of sample), Acharya et al. (69.33\%). ${ }^{7}$

The mean age of the patients was $17.68 \pm 5.21$ years with the age ranging from 9 years to 40 years. The $65.6 \%$ patients were from the age group 9 to 18 years which is similar to Piya et al. ${ }^{8}(39.7 \%)$ and JN Sharma ${ }^{6}$.

In this study the prevalence of Class I malocclusion $(65.9 \%)$ is more than the data reported by Celikoglu et al. ${ }^{9}$, Onyeaso ${ }^{5}$ who reported that $41.5 \%$ and $50.0 \%$ of the sample examined had class I malocclusion respectively. When this study is compared to other studies conducted 
in Nepal, the reported value is more than data reported by Piya et $\mathrm{al}^{10}(50.5 \%)$, Pandey et al ${ }^{10}(61.62 \%)$, in consensus to the data reported by Acharya et $\mathrm{al}^{9}(63.33 \%)$ and $\mathrm{JN}$ Sharma8 $(67.5 \%)$ but less than data reported by Baral ${ }^{11}$ (71.5\%).

The prevalence of Class II malocclusion (31.8\%) in the present study was less than that reported by Celikoglu et al. ${ }^{9}$ with the reported value to be $38.3 \%$, Pandey et $\mathrm{aP}$ (33.47\%), Acharya et $\mathrm{al}^{7}(36 \%)$ and Erum, Fida ${ }^{10}(70.5 \%)$ but more than the data reported by Piya et al. ${ }^{8}(26.7 \%), \mathrm{JN}$ Sharma ${ }^{6}(28.8 \%)$ and Baral ${ }^{11}(24.6 \%)$. The prevalence of class III malocclusion in the present study (5.3\%) is close to data reported by Pandey et $\mathrm{al}^{10}(4.6 \%)$, Baral ${ }^{11}(4.1 \%)$ $\%)$, JN Sharma ${ }^{6}(3.7 \%)$ and Thilander et al. ${ }^{4}(5.8 \%)$ but less than that reported by Celikoglu et al. ${ }^{9}(16.7 \%)$, Piya et $\mathrm{al}^{8}(13.7 \%)$ and Erum, Fida ${ }^{12}(10.9 \%)$. The differences between the prevalence of malocclusion might be due to ethnicity differences.

The most frequently encountered occlusal trait was increased overjet (62.3\%) which is more than that reported by Pandey et al. ${ }^{10}(58.99 \%)$, Acharya et al. ${ }^{7}(40 \%)$, Piya et al. ${ }^{8}(48.9 \%)$, Celikoglu et al. ${ }^{9}(41.7 \%)$. The difference between the prevalence of increased overjet could be due to habits and ethnic variation. Male (62.3\%) and female (59.7\%) had increased overjet in the present study and is not significant. Negative overjet was observed in $2.8 \%$ of the patient in the present study which is less than that observed by Pandey et al..$^{10}(4.6 \%)$, Gelgor et $\mathrm{al}^{5}(10.4 \%)$. In the present study, the increased overjet data was followed by increased deep bite (49.2\%) which is less than that reported by Pandey et al..$^{10}(67.36 \%)$, Piya et al. ${ }^{8}(56.5 \%)$ close to that reported by Acharya et al. $^{7}(46.66 \%)$ more than that reported by Baral ${ }^{12}(29.5 \%)$, Celikoglu et al. ${ }^{9}(36.6 \%)$ and Gelgor et al. ${ }^{5}(18.3 \%)$. When the association of deep bite was calculated with gender, increased deep bite was more frequent in male (58.5\%) than in female (42.5\%). The prevalence of open bite $(2.5 \%)$ in the present study was less than that reported by Shrestha and Shrestha ${ }^{13}(8 \%)$, Celikoglu et al. ${ }^{9}(10 \%)$, Pandey et $\mathrm{al}^{10}(4.6 \%)$, Baral ${ }^{11}(8.9 \%)$ and Gelgor et $\mathrm{al}^{5}$ $(8.2 \%)$ but more than that reported by Piya et al ${ }^{8}(0.8 \%)$.

Crowding was present in $42.58 \%$ in the present study which is more than that reported by Baral ${ }^{11}(10.5 \%)$ and Pandey et al. ${ }^{1} 1$ (35.98\%). Both upper and lower dental arches was the most frequent space discrepancies recorded with value of $70.3 \%$. This value is close to that reported by Gelgor et al. ${ }^{5}$ (65.2\%).
The prevalence of spacing in this study for upper dental arch $(22.1 \%)$ was in consensus to data reported by Piya et al. ${ }^{8}(22 \%)$, and lower dental arch (1.9\%) was considerably less than the data reported by Thilander et al. ${ }^{4}(25.9 \%)$, Celikoglu et al. ${ }^{9}$ (12.5\%).

Bimaxillary protrusion was present in $17.7 \%$ of the patient in this study which is more than the study conducted by Pandey et al. ${ }^{12}(1.67 \%)$. This could be due to the ethnic variation.

The epidemiological data on the prevalence of malocclusion is an important determinant in planning appropriate levels of orthodontic services, so further studies are required to provide accurate estimates of orthodontic treatment in population of Province 2, Nepal.

\section{CONCLUSION}

Angle's class I was the most prevalent malocclusion followed by class II and class III. Increased overjet was the commonest occlusal trait. There was statistically significant association between the age and occlusal traits like crowding, spacing and overjet and none of the attributes of malocclusion were significantly related with gender.

Acknowledgement: We would like to express our deep sense of gratitude to Ms. Babita Singh, Associate professor, Nursing Campus, for her immense support during the journey of execution of research project. Our heartfelt thanks are extended to the institutions that gave us the permission and extended full co-operation in completion of this project.

\section{OJN}




\section{REFERENCES}

1. Proffit WR, Fields HW, Sarver DM. Contemporary Orthodontics. 4th ed. India: Mosby, Health Science imprints of Elsevier; 2008: 3-23.

2. Hassan R, Rahimah AK. Occlusion, malocclusion and method of measurements-an overview. Archives of Orofacial science.2007; 2:3-9.

3. Onyeaso CO. Prevalence of malocclusion among adolescents in Ibadan, Nigeria. Am J Orthod Dentofacial Orthop. 2004; 126:604-7.

4. Thilander B, Pena L, Infante C, Parada SS, Mayorga C. Prevalence of Malocclusion and Orthodontic Treatment Need in Children and Adolescents in Bogota, Colombia. An Epidemiological Study Related to Different Stages of Dental Development. Eur J Orthod. 2001; 23(2):153-67. doi: 10.1093/ejo/23.2.153

5. Gelgör IE , Karaman Al, Ercan E. Prevalence of Malocclusion Among Adolescents in Central Anatolia. Eur J Dent. 2007;1(3):125-31

6. Sharma JN. Epidemiology of malocclusions and assessment of orthodontic treatment need for the population of eastern Nepal. World J Orthod; 2009, winter ; 10(4):311-6.

7. Acharya A, Bhattarai B, George D, Bhagat T. Pattern of Malocclusion in Orthodontic Patients in South-Eastern Region of Nepal. Orthodontic Journal of Nepal, 2017; 7 (1): 7-10

8. Piya A, Shrestha VB, Acharya J, Khanal S, Bhattarai P. Pattern of Distribution of Malocclusion among Patients Seeking Orthodontic Treatment at Dental College. Journal of Nepal Dental Association. 2013; 13(2):36-41

9. Celikoglu, Akpınar, Yavuz. The pattern of malocclusion in a sample of orthodontic patients from Turkey. Med Oral Patol Oral Cir Bucal. 2010; 15 (5):791-6.

10. Pandey et al. Pattern of Malocclusion in Patients Seeking Orthodontic Treatment at Medical Colleges \& Teaching Hospitals of Chitwan, Nepal. Orthodontic Journal of Nepal. 2018;8;2: 41-4

11. Baral. Prevalence of Malocclusion in Western Nepal. Orthodontic Journal of Nepal. 2015: 5; 2: 6-8

12. Erum F. Pattern of Malocclusion in Orthodontic Patients: A Hospital Based Study. Ayub Med Coll Abbottabad. 2008; 20(1):43-7.

13. Shrestha, Shrestha. An Analysis of Malocclusion and Occlusal Characteristics in Nepalese Orthodontic Patients. Orthodontic Journal of Nepal. 2013; 3(1): 19-25 